\title{
Beleza e construção do corpo em narrativas de mulheres sobre a infância
}

\author{
Beauty and body building in women's childhood narratives \\ Vanessa Paula Ponte ${ }^{1}$ \\ Dentro de mim há uma criança que se \\ recusa a morrer
}

(Tove Ditlevsen)

Resumo: Este artigo tem como foco principal as narrativas sobre as infâncias de mulheres cearenses, praticantes de musculação. $\mathrm{O}$ texto aborda as vivências destas mulheres em diferentes situações do cotidiano. Fundamentada na teoria socioantropológica do corpo é problematizado o fluir de seus cotidianos infantis, instante de sua formação em que eram estimuladas a acreditar que uma mulher, para ser valorizada, deveria ser bonita e vaidosa. Vislumbra-se que voltar o olhar para as infâncias dessas mulheres constitui uma importante chave para se compreender o modo como elas se relacionam com seus corpos atualmente.

Palavras-chave: Corpo, beleza, infância, respeito estético.

\begin{abstract}
This article focuses on women's childhood narratives about their corporal images. Anchored in a socio-anthropological theory of the body, the text explores the day-to-day memories of women that workout related to beauty and vanish feminine values. The main goal is understand how these women deal with their bodies actually, from memories of symbolic transmission of esthetic values.
\end{abstract}

Keywords: Body, beauty, childhood, esthetic respect.

${ }^{1}$ Professora supervisora da disciplina de Antropologia Cultural pelo Ensino de Educação a Distância (UAB) pela Universidade de Brasília (UNB) para o departamento de Artes Cênicas. E-mail: nessaponte@gmail.com.

Latitude, Vol. 9, no 2, pp. 07-28, 2015

DOI: https://doi.org/10.28998/2179-5428.20150202 
Beleza e construção do corpo em narrativas de mulheres sobre a infância

\section{Introdução}

O presente artigo nasce de um trabalho anterior ${ }^{2}$ que teve como foco interpretar as narrativas biográficas de mulheres cearenses, praticantes de musculação, e suas experiências em relação à aparência física no cotidiano do trabalho, do lar e em outros momentos de interação social. Com base nessas narrativas, o trabalho ofereceu uma compreensão de como essas mulheres, pertencentes a diferentes realidades sociais, econômicas e culturais, vivenciam seus corpos, os sentimentos daí deflagrados e, principalmente, o que essas experiências dizem sobre o contexto social em que estão inseridas. As narrativas biográficas foram construídas - nos termos de Kofes (1994) - como fonte de inspiração do meio social, como uma evocação do sujeito e uma reflexão da relação entre biografado e pesquisador. ${ }^{3}$

O citado trabalho apontou como são muitos os estímulos e as pressões em nosso meio social para a conquista de um determinado padrão estético: o processo de socialização, o mercado da beleza, os meios de comunicação de massa. Tal padrão corporal é amplamente difundido

2 Dissertação apresentada ao curso de Mestrado em Sociologia da Universidade Federal do Ceará, como requisito para a obtenção do grau de mestre, em setembro de 2008.

${ }^{3}$ As narrativas biográficas, fundamentos etnográficos da pesquisa que embasa este artigo, permitem conhecer, com riqueza de detalhes, as minúcias de cada sujeito da pesquisa; partindo do mais elementar - no sentido do que é possível ser visto com certa facilidade (como se veste, seus diálogos, seus movimentos) - ao mais profundo (o que sente e o que pensa). Fazendo uso dessa metodologia, o pesquisador conhece profundamente não só as vivências desses sujeitos, mas o contexto social em que eles estão inseridos. A fecundidade do método etnográfico pautado nas narrativas consiste em justamente mostrar como a experiência individual é uma fonte rica para se compreender o social. Sobre o método, ver Kofes (2004). 
como garantia de sucesso, poder e felicidade nas mais diversas áreas da vida do ser humano (no trabalho, no relacionamento amoroso, nas interações sociais). Neste sentido, a pesquisa buscou demonstrar como as mulheres analisadas construíram, desde a mais tenra idade, as relações com seus corpos, em diálogo com esse discurso corrente. Muito mais do que isso, o trabalho pretendeu percebê-las de formas integral, estando atento às cobranças sociais em relação aos seus rostos, corpos e idades.

Seguindo tal linha de pensamento, pauto neste artigo algumas passagens das narrativas relacionadas às infâncias de mulheres que participaram do estudo. O objetivo, aqui, é o de refletir sobre as tramas vertentes de sentidos e significados - que faziam parte de seus processos educativos, enfatizando, principalmente, as implicações de tais processos na construção dos seus olhares em relação aos seus corpos. Ao recompor passagens dessas narrativas pretendo iluminar temas mais amplos da vida social, tais como as relações entre individualidade/sociedade, exigências sociais/discriminação, processo de socialização/construção do corpo, cultura/mercado.

Ao dialogar com alguns autores que abordam a temática corporal, trabalho as seguintes questões: quais foram os ensinamentos que essas mulheres receberam desde a infância para lidar com suas aparências físicas? Como elas vivenciaram tais ensinamentos nos processos de socialização? Que implicações físicas e emocionais resultaram destas vivências? O que isso comunica sobre o contexto social em que estavam inseridas? Quais as relações existentes entre o modo como lidavam com seus corpos na infância e o modo como lidam atualmente?

Cabe destacar, que a análise da infância dessas mulheres constitui uma importante chave para se compreender a relação que elas estabelecem com seus corpos atualmente. Corroboro, assim, a ideia de Del Priore (2004, p. 8), quando diz que "olhar para trás" é um saudável exercício que ajuda a iluminar os caminhos que agora percorremos, entendendo o porquê de certas escolhas feitas.

Cumpre salientar ainda, que para construir a pesquisa a qual embasa este artigo, acompanhei de perto, por mais de dois anos, mulheres plurais e os processos por elas vividos na tentativa de construção de um corpo considerado socialmente belo. Construí uma relação dialógica (GEERTZ, 1989) e, com todo respeito e sutileza, vivenciei os seus cotidianos, frequentei as academias em que exercitaram seus corpos, os 
Beleza e construção do corpo em narrativas de mulheres sobre a infância

salões de beleza onde cuidaram do visual. Além disso, participei também de seus momentos de lazer e, de forma especial, visitei amiudadas vezes seus lares. ${ }^{4}$

Durante o trabalho de campo, percebi que, apesar dos seus distintos modos de vestir, falar, gesticular e interagir, bem como, da diversidade de fenótipos, idades, profissões e nível de escolaridade, elas possuíam percepções semelhantes em relação a importância do embelezamento dos seus corpos para suas vidas. Para elas, a imagem corporal constitui elemento preponderante para definir quem deve ou não ser amado, respeitado ou ridicularizado. Assim, por meio da modelagem dos corpos, essas mulheres acreditavam conseguir mostrar quem de fato são, obtendo, em consequência, a aceitação social plena. Tal percepção em relação às

${ }^{4} \mathrm{O}$ ponto de partida para o encontro com as mulheres com as quais interagi em pesquisa foram duas academias - uma de pequeno e a outra de grande porte localizadas na cidade de Fortaleza, no Ceará. Tais espaços atendem pessoas de diferentes realidades sociais, poderes aquisitivos e idades. A primeira das academias, de grande porte, estava localizada na Aldeota, zona norte da cidade. Este bairro possui grandes e arborizadas avenidas em que se encontram várias sedes de empresas imobiliárias, judiciárias, centros comerciais e shopping centers. A academia ali localizada possuía dois pavimentos com salas amplas e arejadas, e a pintura em perfeito estado. Havia também lanchonete, lojas de roupas e de acessórios para atividades esportivas. A sala de musculação era repleta de espelhos, possuía muitos aparelhos e todos eram modernos e estavam em ótimo estado conservação. Já a academia de pequeno porte ficava situada em um dos bairros com menores índices de desenvolvimento humano (IDH) de Fortaleza: o Jangurussu, que fica localizado no lado leste do município, pertencendo à zona urbana mais populosa, constituindo-se de vários conjuntos habitacionais, entre eles o conjunto Palmeiras e o conjunto São Cristóvão. Neste bairro foi construído o aterro de lixo de Fortaleza. A região abrigou, em décadas anteriores, os imigrantes do interior do estado, fugidos da seca, além de inúmeros trabalhadores, em sua maioria desempregados. A referida academia possuía salas pequenas, com o chão em cimento, e as paredes com as pinturas bem desgastadas. A sala de musculação era pouco espaçosa, com ventilação e iluminação precária, aparelhos e espelhos reduzidos e deteriorados pela ação do tempo. Mesmo com todas essas diferenças, observa-se, em ambas as academias, o esforço de seus proprietários em construírem ambientes organizados com horário de funcionamento, regras e higienização. 
aparências físicas vem sendo fortemente estimulada, em suas trajetórias de vida, desde a infância.

\section{Beleza e construção do corpo: os aprendizados das meninas que ressoam nas mulheres}

No presente trabalho, serão apresentadas as passagens das narrativas biográficas das infâncias de Safira, 45 anos, empresária do ramo imobiliário; Ametista, 42 anos, cabeleireira; Rubi, 61 anos, pedagoga e exfreira; Cristal, 25 anos, estudante universitária; e Pérola, 28 anos, vendedora ambulante e diarista. ${ }^{5}$ Elas buscam - com todo vigor - um corpo esculpido pelos exercícios físicos, com ausência de gordura localizada e com o aspecto jovial; almejam também uma pele macia, sem celulite, estrias ou varizes; um rosto livre de linhas de expressão, rugas, espinhas, olheiras; um corpo adornado e vestido de forma adequada para cada ocasião.

Para construírem essa aparência física, elas exercem sobre seus corpos um trabalho diário e minucioso, que envolve uma série de práticas que demandam investimento de tempo, energia e dinheiro: o controle com a alimentação, o uso de produtos estéticos, o rigor com o exercício físico. Do acordar ao dormir, dedicam-se com afinco à beleza física ${ }^{6}$ e, de forma especial, a outras belezas advindas desta (assim elas supõem), ou seja, à beleza de ser apreciada, à beleza do olhar de admiração e, sobretudo, ao olhar de respeito do outro.

Em suas narrativas biográficas, estas mulheres mencionam os ensinamentos que receberam na infância ${ }^{7}$ acerca dos cuidados com a

\footnotetext{
${ }^{5} \mathrm{Na}$ relação dialógica entre pesquisadora e protagonistas da pesquisa firmou-se o acordo de que seus nomes verdadeiros não seriam revelados.

6 A beleza física é vista neste trabalho como algo que vai além da simples geometria física. Ela é ação e comportamento ligados à dimensão social. Corresponde às mudanças econômicas, sociais e culturais de cada momento histórico. Cada coletividade vai ter uma maneira diferente de concebê-la. Até numa mesma coletividade há muitas concepções de corpo belo. Ver: Del Priore (2006), Vigarelo (2006).

${ }^{7}$ No que concerne ao entendimento sobre infância, tomei como base as reflexões de Aries (1978), Dolto (1999), Meyer (2002), Motta (2002). Tais pensadores mostram, a seu modo, como essa fase da vida não pode ser vista meramente como um dado biológico absoluto, mas como histórica e socialmente contextualizada. A infância
} 
Beleza e construção do corpo em narrativas de mulheres sobre a infância

aparência física e revelam como tais ensinamentos foram relevantes para o desenvolvimento desse processo vivido por elas na busca do corpo idealizado. Ora com semblantes suaves, iluminados por sorrisos, ora com os semblantes tensos, muitas vezes tomados por lágrimas, elas remeteram, por meio de suas vozes, a tempos e espaços distintos, em que seus corpos davam os primeiros passos e começavam a descobrir o mundo. Partilharam comigo suas lembranças relacionadas à convivência com familiares, amigos e vizinhos. Relembraram-se de gestos e palavras de carinho, aconchego, orientação, restrição, raiva, cerceamento e impaciência dos adultos que as cercavam, bem como, dos silêncios e ausências de alguns deles. Contaramme as relações que estabeleceram com as outras crianças e as emoções, as alegrias e os desafios que experimentavam nas brincadeiras; também rememoraram momentos vividos na época de escola. Partilharam lembranças de lugares, acontecimentos, aprendizados e sentimentos do seu vivido corporal, quando eram crianças, dando testemunho de como tudo isso repercutiu em suas vidas naquele momento e como ainda vive e viceja no presente.

Desse modo, cada biografada construiu - de uma maneira particular - a forma de contar as suas vivências e experiências, o que pensa sobre suas ações, sobre as ações dos outros com quem partilha ou partilhou a vida e a compreensão de seu entorno. Em suas falas, elas selecionaram aquilo que, ao longo de suas vidas, havia lhes marcado profundamente. Deram ênfase a alguns momentos, não citam outros, mencionam algumas redes de relações, enquanto outras não. Cabe ressaltar, que durante a realização e a análise das entrevistas, sempre tive em mente o princípio de que o importante para o pesquisador são os sentidos e significados que o sujeito de sua pesquisa constrói em relação às lembranças que traz na narrativa.

Nesse exercício de reflexão, a memória é compreendida nos termos de Pollak (1989; 1992), isto é, como algo que se refere ao passado, mas se atualiza na vivência do presente. Desse modo, não encaro a vida das

é, portanto, uma criação arbitrária. Os estudos de Cohn (2005), Louro (2001), Sirota (2001), Cosaro (1997), Sarmento (2007) também foram inspiradores, pois desnaturalizam a ideia de que as crianças estão meramente sujeitas a um processo de socialização e que recebem esse processo de forma mecânica e sem reflexão. As crianças são protagonistas dos processos educativos cidadãos, pessoas que produzem cultura. 
mulheres como algo que tem um sentido único e fixo e nem busco as versões verdadeiras e falsas de seus depoimentos. Essa forma de olhar é rígida e empobrece a pesquisa, já que não leva em conta o dinamismo, a fluidez, a complexidade, as descontinuidades da vida e tampouco considera que o indivíduo pode oferecer múltiplas interpretações sobre sua trajetória. Por meio das memórias, os indivíduos, segundo Pollak, acabam (re)construindo e (re)definindo o seu lugar social e suas relações com os outros.

Seguindo essa linha de raciocínio, apresento, a seguir, algumas práticas de embelezamento que as mulheres pesquisadas realizam para alcançar determinado padrão de beleza. Em seguida, exponho alguns relatos dos ensinamentos que receberam em suas infâncias para lidar com suas aparências físicas. Após esta apresentação, dialogo com alguns autores da bibliografia relacionada à temática corporal, oferecendo uma possibilidade de interpretação dessas narrativas. ${ }^{8}$

Rubi, 61 anos, pratica com disciplina musculação e hidroginástica na academia de grande porte supracitada. Compra praticamente tudo o que ouve dizer que faz bem para a saúde, que auxilia a "viver mais" é contribui para deixá-la mais bonita. Mostra-se extremamente cuidadosa com sua aparência física. Almeja muito emagrecer. Sua nécessaire impressiona pela variedade e quantidade de produtos de beleza que carrega.

Esta senhora, ao falar da infância, rememora - com voz de grande saudade - a sua mãe, a qual descreve como sendo uma mulher séria, de olhar imponente, que não conversava muito com os filhos e que, conforme suas palavras, "não era muito de chamego, de beijo e abraço meloso, era mais de cuidado com a saúde de cada filho, de alimentar, de vestir, de educar". Desse modo, Rubi traz como uma das lembranças mais caras da sua meninice os momentos em que a mãe permitia que ela observasse sua produção, o que, aos olhos de Rubi, representava momentos de proximidade e intimidade entre as duas.

8 O leitor perceberá que registrei literalmente os depoimentos das entrevistadas, não suprimindo possíveis inadequações linguísticas. O modo como falam expressa também suas vivências, suas particularidades. As mudanças realizadas ocorreram para satisfazer o desejo de algumas entrevistadas que - tendo acesso às transcrições - quiseram modificar alguns registros. 
Beleza e construção do corpo em narrativas de mulheres sobre a infância

Minha mãe era uma mulher bonita! Bem alta. Ela gostava de se cuidar, de se vestir bem, de cuidar do cabelo, vivia impecável! Tinha um porte, entende? Era elegante, gostava de se arrumar. Muito feminina! Eu lembro que eu, bem pequena, e uma das coisas que eu mais gostava era ficar olhando ela se arrumar num espelho grande que tinha no quarto dela. Ela olhava pra mim e dizia que não tem nada demais a gente ser mais bonita, ficar mais bonita. Então eu aprendi isso com ela. E foi de tanto que eu olhava pra ela que eu achava que uma mulher tinha que ser arrumada, ser penteada, ser perfumada.

Safira, 45 anos, é também frequentadora da academia de grande porte. Afirma que chegou a pesar mais de 100 quilos; trava uma batalha contra a obesidade desde a infância: toma remédios, faz dietas, utiliza cosméticos nacionais e importados, pratica exercício físico, vai ao SPA. Para alcançar o corpo que sempre sonhou, se submeteu a uma cirurgia de redução do estômago.

Ela suspira profundamente ao rememorar seu tempo de infância. Conta que tinha tudo para ser a menina mais feliz do mundo, pois teve os brinquedos, as roupas, as viagens que desejou. No entanto, não era tão feliz, pois até os dozes anos, era considerada - e se considerava - "uma menina muito gordinha". Uma das dores mais contundentes para Safira era o fato de sua obesidade entristecer sua mãe.

Ave! Na cabeça da minha mãe, ela só podia ser vista como uma boa mãe se as pessoas me vissem assim como uma boneca de porcelana [...]. Só que eu era muito gorda e eu sentia que minha mãe ficava triste com isso. Normal, ela queria que eu fosse admirada como minhas irmãs magricelas. Mas se você for ver, Vanessinha, isso até hoje é assim é natural né? Toda a mãe cuida de sua filhinha, com mais zelo, ensinando a cuidar do cabelo, ensinando a cuidar da pele, a regular o peso. Essa coisa toda! Porque menino não, a criação é diferente, a mãe dá um 
banho, penteia o cabelo e diz: - Vai brincar! Menina, ela se interessa em fazer um penteado, vestir um vestidinho para mostrar a menina para as outras pessoas.

Ametista, 42 anos, pratica musculação e ginástica localizada diariamente na academia situada no Jangurussu. Deseja perder $4 \mathrm{~kg}$ e afirma que só se sentirá feliz quando perdê-los. Com este intuito, ela costuma comprar roupas com a numeração menor do que a sua numeração atual. Assim, diariamente, ao abrir o guarda-roupa, ela renova sua vontade de ficar mais magra para vestir os modelos. Costuma fazer jejum e tomar laxantes nas vésperas das ocasiões especiais na intenção de ficar com a silhueta mais esbelta.

Num tom saudoso, conta como era sua relação como a avó e como essa a estimulou, desde pequena, a dar prioridade aos cuidados com a beleza. Ametista relata que os ensinamentos de avó foram eficazes em sua vida.

Mulher, ela fazia comparação de mim com as outras crianças. Ai! Que a neta da comade Raimunda Ramo é muito magricela, sem graça. Aí... Que a filha da Maria Quixeré é feia parece um tussui. Sempre tinha um defeito! Só quem era bonita era eu. Ela andava nas casa e dizia: - Vem cá fulano, olha minha neta como é linda! Me matava de vergonha! A véinha me acostumou mal. Ela botou na minha cabeça que o meu vestido tinha que ser sempre o mais bonito. Que eu tinha que ser a menina mais bonita da missa, do leilão, da quermesse. Eu lembro que na época as roupas da moda era muito babado, quanto mais babado o vestido era mais caro, pouco babado o vestido era fraco. O meu, ela costurava com oito babados. Aí, o que é que acontecia? Quando não tinha condição de fazer esse vestido de oito babado, quando não tinha o dinheiro pra fazenda, eu esperneava, chorava, não queria sair de casa. Botava um boneco amoado! Era assim, minha 
Beleza e construção do corpo em narrativas de mulheres sobre a infância

filha! [...]. A véinha reparava se eu tava de pé no chão. Dizia que era pra eu ficar calçada pro meu pé num ficar grosseiro. Pé de menina tinha que ser fino, bem cuidado. Eu adorava ficar de pés descalço sentido a terra, adorava e pra fazer isso só escondido dela! Ela não podia me vê sentada torta, relaxada, que vinha com um pauzinho me bater bem aqui [toca em suas costas] pra eu me endireitar. Até esfregar areia nos meus dentes pra eles ficarem brancos ela me obrigava, mandava também eu passar juá pros dentes ficarem branco, era amargo que só, um sacrifício! Porque, naquele tempo, no interior num tinha pasta, né? [...]. Na hora que ela ia lavar o arroz, ela pegava aquela água do arroz e passava no meu rosto que era pra quando eu ficasse maiorzinha num ter espinha [...]. Ela me levava pra nadar no rio que era pra eu num ficar gordinha e me dava feijão e vitamina porque eu também num podia ser magra demais porque no interior uma menina com o osso da perna, batendo, no outro era pior do que ser gorda. As pessoas magras demais eram as pessoas mais horríveis do mundo. As pessoas famosas eram aquelas nem gordas nem magras, ter carne nos lugares certo, ser vistosa [...]. A véinha abria meus olhos me mostrando que a beleza era tudo na vida de uma mulher. Era importante pra ter a admiração das pessoas, pra arrumar um bom casamento. Tudo!

Pérola, 28 anos, pratica a musculação com vigor. Para ter o físico que almeja, além de se exercitar demasiadamente, ela consome medicamentos sem receita médica, pratica regimes severos e, aos sábados pela manhã, bem cedo, faz longas caminhadas sem destino, embaixo do sol escaldante, no intuito de perder calorias. Leva uma garrafinha de água consigo e só retorna perto da hora do almoço.

Em sua narrativa, ela revelou que, desde criança, sentiu a necessidade de cuidar do seu físico, pois a maioria dos membros da sua 
família materna tem tendência para engordar. A seguir, um relato de uma cena comum em seu cotidiano de menina, na qual se pode perceber a aflição de sua mãe com o fato da filha ser obesa. Quanto mais aflita ficava sua mãe, mais ela cobrava de Pérola os cuidados para não engordar.

Mulher, do mesmo jeito que tinha medo do babau, do véi do saco, do boi da cara preta que minha mãe dizia que ia chamar quando eu tava me danando, eu tinha medo de engordar. Porque ela plantava o terror em mim! Dizia que ser gorda era horrível, que era a sina da família dela e que, se eu não me cuidasse, eu ia ficar igual e que o povo ia mangar de mim e que eu ia ficar pro caritó que nem umas tia minha. Era uma ladainha! Cada carão de lascar! Menina, era osso! Eu me sentia assim, tipo culpada. Eu sonhava que eu tava gorda e aí acordava apavorada em tempo de botar os bofe pra fora, aí pegava no meu braço pra ver se tava fino, na minha bochecha. Eu me lembro que eu pequena, menina véia, sei lá, com seis, sete anos, rezava pedindo a Deus pra ele não me deixar ser gorda como minha mãe e minhas tias.

Cristal, 25 anos, trava uma luta para perder peso: bebe litros e litros de vinagre, se exercita em excesso, faz dietas radicais, toma laxante, práticas estas as quais colocam seriamente em risco sua saúde física e psicológica. Além disso, os cuidados que têm com o corpo não se restringem à questão da alimentação. Ela se banha e se perfuma demasiadamente. Além dos cosméticos, sente uma vontade desenfreada de comprar roupas e sandálias.

Em seu tempo de infância, algo que a entristecia era o fato de não ser escolhida rainha nas festas da escola. Cristal comenta quem eram as escolhidas e ofrisson que elas causavam.

Ninguém nunca me escolhia pra ser rainha. Eu sempre quis ser, pelo menos, convocada para participar do processo pré-seletivo. Geralmente, elas 
Beleza e construção do corpo em narrativas de mulheres sobre a infância

eram as meninas lourinhas, dos olhos claros, magrinhas, mas não esqueléticas, como eu era. $\mathrm{O}$ termômetro da beleza também era aquele que quanto mais a menina fosse convocada para eventos, para fazer parte do grupo de dança, para tirar foto para fazer propaganda da escola, mais bonita ela era. As rainhas faziam mais sucesso com as professoras. Tipo, as professoras babavam mais, as meninas eram mais populares, os meninos se interessavam mais. Eu lembro que tinha uma que o apelido era "loirinha". Na época, ela, nós éramos magrelas, e ela tinha um corpo lindo. Tinha um menino que eu achava lindo. E ele falava muito da loirinha e isso, a loirinha era aquilo, e eu chorava porque eu queria que ele falasse de mim.

A seguir, aponto uma possibilidade interpretativa para estas passagens narradas pelas entrevistadas a respeito de suas infâncias. Para tanto, ancoro a análise em alguns autores da literatura sobre a temática corporal.

\section{A ânsia pela beleza nas memórias de um aprendizado}

As passagens narrativas descritas expressam claramente que as mulheres pesquisadas, por mais que fizessem parte de tempos e contextos distintos, desde a mais tenra idade, conviveram com pessoas que diariamente expressavam, por meio de gestos e palavras, uma intensa preocupação com a aparência física. No fluir de seus cotidianos infantis, elas eram estimuladas, ou até mesmo coagidas, a acreditar que uma mulher, para ser valorizada, deveria ser bonita e vaidosa. Assim, elas tiveram muitos influências e ensinamentos para cuidarem de suas aparências físicas como uma prioridade, uma vez que isto era visto como um fator fundamental para conseguir o respeito do outro e a aceitação social.

Este discurso, ou seja, o de que deveriam cuidar de sua imagem corporal, foi muito propagado pelas mulheres significativas em suas vidas (irmãs, avós, mães, tias, vizinhas etc.) nos processos educativos ao longo de suas infâncias. Ao contrário do que se pensa comumente, a ideia de que 
mulheres devem ser vaidosas, zelosas com seus corpos e dedicadas ao embelezamento de suas aparências, nem sempre foi propagada socialmente. Del Priore (2005) nos conta que no Brasil Colônia, por exemplo, era preciso que a mulher não tivesse vaidades e ignorasse a beleza física, pois esta era temida, uma vez que se associava diretamente a mulher a um instrumento de pecado (DEL PRIORE, 2005, p. 30). Tal discurso era propagado, sobretudo pela Igreja, que tinha à época uma forte influência em muitos lares.

Há uma vasta bibliografia nas Ciências Sociais mostrando que, a partir da segunda metade do século XX, no Brasil, e em seus mais diferentes contextos, propagavam-se com vigor discursos sociais que entendiam a aparência como uma "estratégia social de poder", sendo que a beleza física, especialmente a das mulheres, era vista como algo que deveria ser exaltado, valorizado, exigido e buscado intensamente (BEZANESSI, 1994; 2006; COUTINHO, 1994; DEL PRIORE, 2005; SANT'ANNA, 1999; CASTRO, 2004;). De lá para cá, tais discursos que incitam tanto as mulheres quanto os homens a empreenderem um trabalho meticuloso, atento e sistemático de embelezamento em suas imagens, vêm se intensificando cada vez mais, respaldados por muitas instâncias sociais: indústrias de cosméticos, do emagrecimento, medicina estética, meios de comunicação de massa e tantas outras. Sobre os discursos preponderantes em relação ao corpo nas sociedades contemporâneas Le Breton afirma:

É por seu corpo que você é julgado e classificado (...) Nossas sociedades consagram o corpo como emblema de si. É melhor construí-lo sob medida para derrogar ao sentimento da melhor aparência. Seu proprietário, olhos fixos nele mesmo, cuida para torná-lo seu representante mais vantajoso. As condições sociais e culturais dos indivíduos certamente matizam essa consideração, mas esse é, pelo menos, o ambiente de nossas sociedades humanas com relação ao corpo. Se em todas as sociedades humanas o corpo é uma estrutura simbólica, torna-se aqui uma escrita altamente reivindicada, embasada por um imperativo de se 
Beleza e construção do corpo em narrativas de mulheres sobre a infância

transformar, de se modelar, de se colocar no mundo (LE BRETON, 2003, p.31).

As narrativas biográficas das entrevistadas evidenciam que esses discursos possuíam um lugar central nas vidas das mulheres que as ensinaram a dar os primeiros passos, de modo que tais discursos passaram a ocupar lugar significativo também em suas vidas. As suas tias, avós e irmãs mais velhas manipulavam diariamente produtos de embelezamento, com elas sempre por perto, ali observando e aprendendo. Desse modo, as vivências na educação familiar foram contundentes para as suas percepções em relação ao embelezamento de seus corpos. As cenas descritas remetem a Mauss (1974), sobretudo no que se refere ao conceito de imitação prestigiosa, o qual consiste, justamente, no fato dos indivíduos, desde a mais tenra idade, assumirem os comportamentos, as atitudes e os corpos que, em seu grupo social, alcançaram êxito e tornaram-se bem-sucedidos (MAUSS, 1974, p. 215).

Ampliando essa ideia de imitação prestigiosa remeto-me ao trabalho de Cohn (2005) a respeito dos Xikrin, subgrupo Kayapó, de língua Jê, habitante do sudoeste do Pará. A autora faz uma discussão sobre o modo como eles concebem a infância e o desenvolvimento infantil. Cohn desnaturaliza uma ideia corrente em nosso meio social de que a experiência da criança é uma mera imitação, do mundo adulto. Mostra-nos como tal experiência é qualitativamente diversa e particular e como é marcante para a inserção em seu contexto social. Segundo a autora:

É a partir das experiências das crianças que estas podem mapear os contextos e as relações sociais que constituem a sociedade em que vivem, e nela atuar de um modo que não se confunde com o dos adultos. De fato, como vimos, em diversos momentos o que elas fazem pode parecer uma imitação do mundo adulto(...). No entanto, o que as crianças estão fazendo não é uma mera imitação do mundo adulto, mas uma constituição ativa de relações sociais que as acompanharão por toda a vida. 
Baseada no trabalho de Cohn é possível perceber os gestos de embelezamento e os cuidados com a aparência física executados nas infâncias das mulheres com quem interagi em pesquisa para muito além da mera imitação. Nas práticas diárias e detalhadas que elas exerciam sobre suas imagens, como o vestir-se, o maquiar-se, o adornar-se, estavam expressas diferentes significações sociais. Tais gestos, vivenciados e resinificados, foram sedimentando, ao longo de suas trajetórias, práticas e valores que disseminam a ideia de que o indivíduo está relacionado à sua forma física. As passagens das narrativas, as quais apontam os gestos esboçados pelas mulheres quando crianças na preparação de suas aparências físicas e que mostram as meninas se embelezando, são, na verdade, o início e a efetivação de uma relação com o corpo que poderá durar por toda a vida.

Na socialização escolar, também aprenderam que para ter um lugar especial entre os seus, como diz o poeta, a "beleza é fundamental". Isso fica evidente nos desfiles de rainhas de sala, promovidos nos colégios, comentado na narrativa de Cristal. Tais desfiles promovem de forma intensa a ideia de que quem se destaca pela beleza colhe frutos positivos nas relações sociais. A narrativa mostra o fato de que as pessoas eleitas em tais concursos apresentavam uma atuação mais positiva em seus espaços de sociabilidade.

Sobre isso, torna-se pertinente o pensamento de Woolf (1992, p. 98), o qual reflete sobre ideias propagadas desde a socialização de muitas meninas em nosso contexto social: "mulheres competem umas com as outras", "invejam umas as outras", "as mulheres considerem umas as outras possíveis adversárias". A autora vai mostrar como estas afirmações são prejudiciais, pois promovem sentimentos de disputa, brigas, competição, quando as mulheres, desde crianças, deveriam aprender a se respeitar, inclusive, se unirem na busca de determinados direitos e interesses.

No curso das narrativas biográficas, podemos vislumbrar técnicas corporais criadas socialmente que visam o embelezamento de cada parte da aparência física. Da cabeça aos pés, nenhum detalhe escapa. O que se pode observar com muita recorrência, ao acompanhar as narrativas biográficas estudadas, é o fato dessas técnicas ou gestos que embelezam serem partilhadas ou até mesmo impostos pelas mulheres mais velhas às mais novas. 
Beleza e construção do corpo em narrativas de mulheres sobre a infância

Sobre isso, cito os regimes que as mães de Pérola e Safira as obrigavam a praticar. E a postura enérgica da avó de Ametista que a disciplinava para que se dedicasse aos cuidados da aparência: ela passava areia e juá em seus dentes para que o seu sorriso ficasse branquinho e impecável, assim como, diariamente, se limpava com a água na qual o arroz acabara de ser lavado, como uma forma deixar o seu rosto livre de espinhas. Andar sempre calçada era outra exigência desta avó, pois pé bonito era o fino e o delicado. Já a mãe de Rubi a estimulava a andar sempre penteada e arrumada.

Pensando nos modos como as protagonistas deste trabalho eram conduzidas a cuidarem de seus corpos, pelas mulheres significativas em suas vidas, podemos relacionar tais acontecimentos àqueles que Clastres (1978) relata quando descreve um ritual de iniciação vivido por alguns membros nas sociedades sem escrita. $\mathrm{O}$ autor descreve que a comunicação entre os indivíduos e sua forma de expressar as leis estão escritas nas superfícies de seus próprios corpos. Cada membro da coletividade traz inscrito, em seu corpo, as marcas da cultura e do ethos tribal. Em seu trabalho, Clastres afirma que os rituais de iniciação, os jovens que estão vivendo a passagem para a fase adulta são submetidos a uma série de atos que, em nossa cultura, classificaríamos como tortura: “Com furos pelo corpo e estiletes enterrados nas chagas, enforcamento, amputação, a derradeira corrida, carnes rasgadas" (CLASTRES, 1978, p.126). As pessoas que ferem os mais novos utilizam-se de inúmeras técnicas para causar a dor e o sofrimento. Fazem isso até o jovem, como eles diriam, ficar morto, ou seja, desmaiado. Para tais indivíduos, essas técnicas não são consideradas formas de tortura e os jovens iniciados vivem todo esse processo com serenidade e bravura. $\mathrm{O}$ fazem, porque disso dependerá sua inserção no grupo. As cicatrizes vão proclamar um pertencimento social e todas as vezes que eles olharem uns às cicatrizes dos outros, nenhuma palavra precisará ser dita para que possam afirmar: "És um dos nossos e não te esquecerás disso" (CLASTRES, 1978, p.128).

Os membros experientes da coletividade querem que o noviço viva uma série de aprendizados focalizados em seu próprio corpo. E a partir deste aprendizado vivido com cada parte do corpo, seja pintando-as, seja marcando-as com feridas, a pessoa sente-se integrada a seu grupo.

Nas narrativas aqui apresentadas vemos, justamente, que as mulheres mais experientes vão compartilhando com as mais novas as 
técnicas necessárias para os cuidados e embelezamento corporais. Compartilham, além disso, o ensinamento de um novo olhar sobre o corpo. As protagonistas deste artigo, quando crianças aprendiam, de forma muitas vezes desconfortável e dolorosa, dia após dia, a dar atenção a cada parte do corpo de uma forma especial. Podemos verificar nas passagens narradas sobre a infância, em que elas começam a avaliá-las, medi-las, compará-las com as partes dos corpos das outras crianças, das outras pessoas. Enfim, começam a discipliná-las.

Então, vemos que, ainda pequenas, passam a querer usar os produtos de beleza e roupas que as mulheres mais velhas usam, a querer praticar determinados gestos que embelezam e que aquelas praticam. E assim, a cada dia, tecem um olhar sobre o seu corpo, semelhante aos olhares que aquelas mulheres significativas em suas vidas tecem sobre os delas. E quando menos esperam, estão completamente em harmonia com a linguagem, com as técnicas, com as angústias, desejos, dilemas e alegrias, que perpassam a busca de um corpo considerado socialmente belo e, mais do que isso, passam a vivenciar e construir, mais e mais, seu contexto social.

Inclusive, observamos que muitos dos elementos utilizados para embelezar os corpos, como roupas e adornos, podem ser comparados ao valor atribuído às cicatrizes das sociedades sem escrita mencionadas por Clastres (1978). Isso porque, as mulheres citadas expressam por meio de suas roupas e de seus adornos os valores sociais inscritos em seus corpos. Da mesma forma, podemos ver os músculos esculpidos pelos exercícios físicos. O corpo, como se conhece, retém em si uma história a contar.

É importante frisar que a intenção deste artigo não é responsabilizar as mulheres significativas no processo de socialização das pessoas com quem interagi em pesquisa (tias, avós e irmãs mais velhas) pelas relações que estas possuem com seus corpos e sim refletir sobre os sentidos do meio social que orientam ou impõem tanto umas quanto as outras a buscarem com intensidade um padrão de beleza. Assim, procuro problematizar sobre o quanto esse padrão exige dos seres humanos, os interesses que estão por trás; também viso questioná-lo, uma vez que ele é restrito, tanto física como subjetivamente, diante da diversidade dos indivíduos.

Destaco que, atualmente, muitas outras crianças se comportam da mesma maneira. Os comentários que escutei ao longo dos anos em que 
Beleza e construção do corpo em narrativas de mulheres sobre a infância

trabalho com esse tema me permitem fazer tal inferência. Presenciei ou soube de casos, como o de uma menina com cinco anos que se recusava a se alimentar, pois dizia estar gorda; outra, com sete anos, perguntou se havia alguma cirurgia capaz de retirar suas sardas; uma terceira, com seis anos, se recusava a usar sandálias baixas e queria calçar apenas sapatos com salto alto; outra garota, com oito anos, só saía de casa se estivesse com maquiagem na bolsa e, além disso, também demonstrava insatisfação com seus cabelos crespos, querendo-os mais lisos.

A Associação Brasileira de Indústria de Higiene Pessoal, Perfumaria e Cosméticos (ABIHPEC), regista que o mercado nacional é o terceiro maior do mundo no segmento infantil, ficando atrás apenas dos Estados Unidos e da China. Nos últimos cinco anos, o setor obteve um crescimento médio de $14 \%$, alcançando um faturamento de $\mathrm{R} \$ 4,5$ bilhões em 2014. Vale mencionar outro estudo que evidência como a incidência da vaidade infantil é forte entre as crianças, sobretudo entre meninas. A Multifocus, instituto de pesquisa de mercado, realizou um estudo com 1.800 brasileiras de 6 a 17 anos sobre os hábitos de beleza e apresentou as seguintes constatações: " $48 \%$ das meninas fazem luzes, $13 \%$ alisam o cabelo em salão de beleza. Oito entre dez meninas usam maquiagem e fazem as unhas. Entre as garotas com menos de 11 anos, 95\% usam batom. Mais de um terço aplica base, corretivo e pó facial."

É imprescindível mencionar que esse desejo por parte de muitas crianças de alcançar determinada beleza física, não raramente, ocasiona males à saúde. Maria de Fátima Fernandes, diretora secretária da Associação Brasileira de Alergia e Imunopatologia ${ }^{9}$ chama a atenção para os possíveis problemas do excesso da vaidade infantil, que podem atingir tanto o âmbito psicológico quanto o físico. O uso incorreto de certos cosméticos e acessórios, como bijuterias, pode desencadear uma forte reação alérgica. $\mathrm{O}$ uso do salto alto pode ser prejudicial à coluna da criança. Além disso, as meninas cada vez mais, estão procurando alisar os cabelos, o que pode ocasionar irritações no couro cabeludo e na pele, como ressecamento e até dermatite atópica. Denize Bernuzzi Sant'Anna (2000) mostra como o consumo exacerbado por produtos e tratamentos estéticos entre as diferentes faixas etárias se deve a razões sociais e culturais:

${ }^{9}$ Disponível em: http://www.sbai.org.br/ 
Vivemos em sociedades que adulam e valorizam o corpo, ao mesmo tempo, o avaliam e o exploram. Por um lado, somos diariamente confrontados com a proliferação acelerada de produtos, tecnologia, terapias e saberes que visam ao fortalecimento e ao embelezamento do corpo; por outro, nos deparamos com sua comercialização desenfreada: no trabalho, nos hospitais, na mídia e também nas ruas, onde cresce a banalização das violências feitas ao corpo, o desrespeito e o descaso com corpos de crianças, jovens e idosos [...] ele [o corpo] também se tornou objeto de imensas curiosidades, de imensas explorações comerciais, de diferentes manipulações científicas e industriais [...] (SANT'ANNA, 2000, p. 245).

Acredito na importância de questionarmos essa exigência cada vez mais intensa de uma imagem padronizada, que aflige crianças, adultos e idosos uma vez que não contempla, nem de longe, os corpos sociais que são fisicamente e subjetivamente tão diversos, além de não contemplar também as outras belezas do ser humano que estão para muito além do físico.

Atualmente, além de conviverem com as memórias de seus processos de socialização, no que tange aos ensinamentos para as vivências de seus corpos, as mulheres com quem interagi na pesquisa convivem ainda com discursos advindos da medicina estética, da mídia, da indústria de embelezamento, os quais propagam a importância de rejuvenescer, potencializar, exercitar, liberar, investir e transformar a aparência física. Tais concepções repercutem nas experiências sociais de seus corpos em diversas dimensões: econômica, simbólica, política e individual. Embasadas nesses aspectos, as entrevistadas afirmavam sentir liberdade e autonomia para intervir em suas aparências físicas e transformá-las. No entanto, percebi na análise de suas narrativas que, por trás desses discursos sobre a liberação da expressão corporal, há regras rígidas para enquadrar os corpos a padrões estéticos que, a cada dia, tornam-se mais exigentes.

Hoje em dia, advoga-se que o corpo está aí para ser vivido, experimentado, exposto, mostrado (RAGO, 2004, p.11). Somos, a todo instante, convidados a administrar a própria aparência, a superar, a 
Beleza e construção do corpo em narrativas de mulheres sobre a infância

redesenhar as formas físicas (COUTO, 2004, p. 135). "A pele tonificada, alisada, limpa apresenta-se idealmente como uma nova forma de vestimenta, que não deve enrugar nem amassar jamais" (DEL PRIORE, 2004, p. 255). Hoje, assistimos a uma proliferação crescente de espaços e técnicas para o cultivo de um corpo belo, uma espantosa proliferação das cirurgias plásticas, incluindo intervenções em nome da beleza (SANT'ANNA, 2004, p. 111). Como afirma Kofes (1994, p. 55): “a cada momento tem-se este deslocamento entre o conjunto de atividades que aprisionam o corpo e aquelas que liberariam o corpo."

Esse padrão contribui para a construção de um olhar incisivo em relação aos corpos, e que considera rugas, fios brancos de cabelos e pele flácida sinônimos de infelicidade. Como argumenta Santanna (2005): a beleza corporal é uma relação. É uma construção. É possível construir novas formas de pensar e encarar as relações dos seres humanos com suas aparências físicas.

\section{Por uma nova forma de olhar o corpo}

A par das diferenças de contextos históricos, culturais, sociais que as meninas Rubi, Safira, Ametista, Pérola e Cristal vivenciaram em suas infâncias, encontramos pontos bem semelhantes, no que diz respeito ao vivido corporal quando eram pequenas. A centralidade que a aparência física assumia em suas vidas e as avaliações que elas teciam sobre suas imagens eram realizadas em referência ao modelo de beleza proposto socialmente; a ideia tão viva em seus cotidianos de que tinham que empreender um constante e intenso esforço para conquistar, manter, ampliar suas belezas físicas; o sentimento de culpa que sentiam, pois acreditavam que, por mais que se esforçassem para conquistar a aparência física socialmente considerada bela, acreditavam que o esforço estava aquém do esperado.

Pelo que pude constatar no curso da pesquisa que embasa este artigo, não só as mulheres aqui citadas, mas muitas outras praticantes de musculação, com as quais interagi, além de outras do meu ciclo de relação, vivenciam esse modo de ver, perceber e lidar com o corpo - e isso se dá desde a mais tenra idade, levando-as a vivenciar o que Wolf (1992) designa de nova ditadura, a do mito da beleza que na concepção da autora, se constitui de forma dura e perversa, uma vez que muitas mulheres se 
encontram permanentemente insatisfeitas com seus corpos, obcecadas com suas próprias imagens, com o pânico de envelhecer, de engordar e de estarem muito aquém da aparência física idealizada socialmente. Para Wolf (1992), essas mulheres ficam presas nelas mesmas, pois estão sempre tensas, ocupadas, pressionadas com uma intensa rotina de cuidados com cada parte do corpo e, por mais cuidados que empreendam, geralmente sentem que seus físicos não são suficientemente belos. Isso as fere e angustia, já que acreditam, desde pequenas, que a beleza física tem uma dimensão importante para alcançar a felicidade. A autora destaca que essa ditadura é a mais contundente já vivida pelas mulheres, pois elas, motivadas ou pressionadas por uma série de exigências sociais, se tornam as censoras, os algozes de si mesmas.

Wolf (1992) afirma, com veemência, que muitos são os prejuízos do mito da beleza nas vidas das mulheres, entre eles o aumento de distúrbios alimentares, como a anorexia e a bulimia, o preconceito contra a velhice e a obesidade, o fato de minar suas energias e concentrações para lutar por possíveis conquistas nos âmbitos legal, profissional, pessoal, entre outros. A autora é firme quando diz que tudo isso atende a interesses de instâncias sociais, como os da indústria da beleza e da mídia, que se beneficiam com uma venda demasiada de produtos e técnicas para os cuidados do corpo. Devo dizer que essas indústrias de embelezamento acabam movimentando um mercado de trabalho grandioso, que abrange uma mão de obra diversificada, advinda de diferentes segmentos sociais: manicures, vendedoras ambulantes, representantes de cosméticos, costureiras, cirurgiões plásticos, esteticistas e outros. Como já mencionado, o Brasil é o terceiro mercado mundial de cosméticos, perfumes e higiene pessoal.

Dialogando com Wolf (1992), acredito que é preciso muita prudência para não generalizar os comportamentos das pessoas diante dos apelos do mercado da beleza, da mídia e da medicina estética. Não se pode dizer que todas as mulheres agem diante desses apelos de forma acrítica e inerte, nem que existe entre elas uma interpretação homogênea acerca desses apelos. Ao contrário, os indivíduos, a partir de suas trajetórias, de suas situações sociais e culturais, conferem sentidos diversos a esses ditames da beleza impostos pela sociedade. Outro ponto que considero importante destacar é que o mercado da beleza não pode ser visto como algoz e os consumidores como vítimas. Na dissertação de mestrado, refleti sobre como a associação de beleza, sucesso e felicidade a um corpo sarado 
Beleza e construção do corpo em narrativas de mulheres sobre a infância

tem levado à prática de dietas abusivas e de outras formas não saudáveis de regular o peso.

Nesse sentido, trago uma reflexão de Louro (2003), o qual diz ser imprescindível admitir que o sujeito não é um mero receptor de pedagogias exteriores a ele, mas que participa, ativamente, desse empreendimento. A autora reconhece que os discursos produzidos e veiculados pelos institutos oficiais de saúde, pelas revistas, pelo cinema, pela internet ou pela indústria moda, produzem certamente efeitos sobre os corpos e as mentes dos indivíduos. No entanto, enfatiza que seus efeitos não são previsíveis, irresistíveis ou implacáveis. Louro nos leva a compreender que os sujeitos não somente respondem, resistem e reagem, como também intervêm em seus próprios corpos para inscrever-lhes, decididamente, suas próprias marcas e códigos identitários e, por vezes, para escapar ou confundir normas estabelecidas.

Este artigo faz reflexão baseado nas recordações de Rubi, Safira, Ametista, Pérola e Cristal, sobre suas meninices, angústias, incertezas, dores, e preocupações que elas vivenciaram, e ainda hoje vivenciam, quando se avaliavam do ponto de vista físico. No entanto, é importante frisar que essas vivências não foram somente áridas, sombrias e dolorosas. Os momentos lúdicos construídos com alegrias e criatividade estiveram presentes em seus cotidianos infantis: prazer de vestir uma roupa nova (mesmo tendo ela sido usada pela filha da patroa), de calçar um sapato novo, de se fazer bonita para alguma festa, de brincar, de se conhecer diante dos espelhos. Acrescento, ainda, que a intenção neste exercício de reflexão não é de forma alguma vitimizá-las e considerar os atores de suas educações familiares como algozes. Essas cinco meninas que conhecemos por meio das mulheres que são hoje, estavam longe de se portar totalmente passivas em seus processos educativos. Elas eram participantes! Eram questionadoras, construtoras de seus cotidianos e não vivenciavam somente momentos de peso e dor em relação aos seus corpos, também vivenciavam momentos de luz e encantamentos: brincadeiras, cantos, sorrisos, danças, descobertas.

No entanto, as narrativas das infâncias mostram que os adultos cuidadores, em referência ao meio social, se valiam do seguinte pensamento: criança tem que se adaptar, se dobrar, se enquadrar aos comportamentos, aos hábitos, às atitudes, aos modos de ser e de sentir reconhecidos no grupo social em que está inserida. As narrativas 
apresentam que isso se expressava, muitas vezes, numa relação desigual entre adulto e criança. Adulto fala e criança tem que calar e acatar! Adulto traça determinado caminho e a criança tem que seguir! Sob pena de castigos, carões, surras, impaciências, chantagens, olhares decepcionados ou sob ganho de elogios, olhares de orgulho, atitudes de carinho e amor. Recordações de suas infâncias, em que suas vozes foram abafadas, seus movimentos corporais foram podados, suas asas foram cortadas, emergiram com frequência e intensidade nos longos diálogos. No entanto, penso que esta forma de educar os corpos e os discursos que conformam o processo educativo é apenas uma possibilidade entre tantas existentes e tantas outras que podem ser criadas.

Trago para este diálogo o trecho de uma obra que nos faz vislumbrar um tipo de processo educativo em que pais e filhos costumavam construir uma relação de igual para igual. Com a palavra, Malinowski:

As crianças nas ilhas Trobriand desfrutam de uma liberdade e uma independência consideráveis. Cedo se emancipam da tutela dos pais, que nunca chegou a ser muito rigorosa [...] não existe nenhuma noção de disciplina regular nem qualquer sistema de coerção doméstica. Aconteceu-me mais de uma vez estar assistindo a um incidente de família ou a uma querela entre pai e filho e ouvir o primeiro dizer ao segundo "faça isto", "faça aquilo": em geral fosse o que fosse, era algo que se pedia como um favor, sem caráter de ordem - ainda que tal pedido pudesse apoiar, vez por outra, uma ameaça de violência. $\mathrm{O}$ mais comum é um pai, quando elogia seu filho, ou o repreende ou lhe pede algo, tratá-lo de igual para igual. Dar ordens, na expectativa de que os filhos as obedeçam, naturalmente, não é próprio dos pais nas ilhas Trobriand (MALINOWSKI, 1983, p.79-80).

Malinowski conta que ele, ao flagrar uma impertinência infantil, sugeria aos Trobriandeses que seria uma boa lição para o futuro bater na criança ou castigá-la deliberadamente de alguma outra maneira. Diz 
Beleza e construção do corpo em narrativas de mulheres sobre a infância

Malinowski: "Tal conselho pareceu a meus amigos imoral e contra a natureza, e foi repelido na mesma hora, não sem certo ressentimento" (MALINOWSKI,1983, p. 80). Como se vê, diferentes tipos de processos educativos resultam em diferentes tipos de ver, pensar e sentir os corpos, as pessoas, as relações, a natureza, enfim, a vida. Pensemos, portanto, em processos educativos que possibilitem a construção de um novo olhar em relação à beleza física. Um olhar que não instaure nas pessoas um sentimento de insuficiência, de culpabilidade e de vergonha, e sim de aceitação.

Pudemos observar, neste trabalho, por meio da fala das entrevistadas, como as exigências em relação à adequação de suas aparências físicas a determinado padrão de beleza ressoaram em histórias particulares e em suas subjetividades prejudicando, por vezes, seu bemestar físico, emocional e social. Em nome desse imperativo que dissemina a ideia de que vale mais o invólucro do corpo do que o seu conteúdo, elas se dedicaram, por exemplo, à prática abusiva de exercício físico, a regimes severos e ao uso de medicamentos para emagrecer. Os sentimentos de insuficiência, de culpabilidade e de vergonha em relação aos seus corpos, são elementos que as acompanham desde a mais tenra idade. Fruto da ideia, como refletem Novaes e Vilhena (2005), de que cabe ao indivíduo a responsabilidade no agenciamento de si, determinando, vigiando, balizando suas próprias ações e seu comportamento. As autoras trazem uma instigante reflexão que mostra que a discriminação contra as pessoas consideradas socialmente feias é manifestada sem culpa, sem nenhum pudor e nem vergonha, ao contrário, daquela que é manifestada em relação ao negro e ao pobre, por exemplo.

A pesquisa aponta, então, que não é a busca da beleza física por si só que adoece, constrange e afeta o cotidiano das pessoas e sim os significados que são atribuídos socialmente a esta busca, em especial, a exigência cada vez mais intensa de um tipo físico que não contempla, nem de longe, os corpos sociais que são física e subjetivamente tão diversos.

\section{Referências}

BASSANEZI, Carla. Mulheres dos anos dourados. In: PRIORE, Mary Del. (Org.). História das mulheres no Brasil. 8. ed. São Paulo: Contexto, 2006. 
Revistas Femininas e o Ideal de Felicidade Conjugal (1945-1964). Cadernos Pagu. São Paulo: Unicamp, 1994. p.111-145.

CAMPOS, Roberta B. Cuidando de si e do futuro: estrutura dos sentimentos nas práticas corporais femininas. In: KOURY, Mauro Guilherme; BARRETO, Maria Cristina Rocha (Org.). Antropologia das emoções. João Pessoa: Grem, 2004. p.7-15.

CASTRO, Ana Lúcia de. Culto ao corpo e sociedade: mídia, estilos de vida e cultura de consumo. São Paulo: Annablume: Fapesp, 2003.

. Culto ao corpo . In: CONGRESSO LUSO BRASILEIRO DE

CIÊNCIAS SOCIAIS. Anais. Coimbra 16, 17 e 18 de setembro de 2004.

Disponível

em:

sitehttp \\www.ces.uc.pt $\backslash$ lab2004 \inscrição \pdfs \painel24\analucia castro. Pdf consultei em 2007.

CLASTRES, P. Da tortura nas sociedades primitivas. In: . A sociedade contra o Estado. Rio de Janeiro: F. Alves, 1978. cap. 10, p. 123-131.

COUTINHO, Maria Lúcia da Rocha. Tecendo por trás dos panos: mulher brasileira nas relações familiares. Rio de Janeiro: Rocco,1994.

DEL PRIORE, Mary. História da criança no Brasil. São Paulo: Contexto, 2004. . História do amor no Brasil. São Paulo, CONTEXTO, 2005.

. (Org.). Histórias das mulheres no Brasil. 8 .ed. São Paulo: Contexto, 2006.

GEERTZ, Clifford. Uma descrição densa: por uma teoria interpretativa da cultura. In: A interpretação das culturas. Rio de Janeiro: LCT, 1989, p. 13-41.

KOFES, Suely. História de vida, biografias, trajetórias. Campinas: UNICAMP, 2004.

LOPES, Louro. Pedagogia da sexualidade. In: O corpo educado: pedagogias da sexualidade. 2. ed. Belo Horizonte: Autêntica, 2001. p. 7- 34.

2003.

. Corpos que escapam. Labrys. Estudos feministas, n. 4, agos. Dez.

LE BRETON, D. Adeus ao corpo: Antropologia e sociedade. Campinas, SP: Papirus,2003. . Sociologia do corpo: Petrópolis, RJ: Vozes, 2006.

MALINOWSKI, Bronislaw. A vida sexual dos selvagens: descrição etnográfica do namoro, do casamento e da vida de família entre os nativos das Ilhas Trobiand. Rio de Janeiro: Francisco Alves,1983. 
Beleza e construção do corpo em narrativas de mulheres sobre a infância

MAUSS, M. As técnicas corporais. In: . Sociologia e antropologia. São Paulo: Edusp, 1974. p. 211-33.

. Ensaio sobre a dádiva. Forma e razão da troca nas sociedades arcaicas. In: Sociologia e antropologia. São Paulo: Edusp, 1974. p. 37184.

O QUE VOCÊ PODE FAZER PELA AUTO-ESTIMA DA SUA FILHA. Revista Cláudia, fev. 2007, p. 46-49.

POLLAK, Michael. Memória e identidade social. Estudos Históricos, Rio de janeiro, v. 5, n. 10, 1992.

Memória, Esquecimento, Silêncio. Estudos Históricos, Rio de janeiro, v. 2, n. 3, 1989.

PONTE, Vanessa Paula. Cada um sabe a dor e a delícia de ser o que é: uma etnografia de duas academias de musculação em Fortaleza. 209f. 2005. Monografia (Bacharelado em Ciências Sociais). Universidade Federal do Ceará. 2005.

- Caminhantes: narrativas biográficas de mulheres praticantes de musculação / Fortaleza. 2008. 246f. Dissertação (Mestrado em Sociologia). Universidade Federal do Ceará. Fortaleza. 2008.

SANTANNA, Denise Bernuzzi de.Cuidados de si e embelezamento feminino: fragmento para uma história do corpo no Brasil. In: (Org.). Políticas do corpo. São Paulo: Estação liberdade, 1999. cap. 7, p. 121-139.

. Entrevista Marta Kanashiro. Consciência - Revista Eletrônica de Jornalismo Científico. 2005.

VIGARELLO, George. História da beleza. Rio de Janeiro: Ediouro, 2006.

WOLF, Naomi. O mito da beleza: como as imagens de beleza são utilizadas contra as mulheres. Rio de Janeiro: Rocco 1992. 